\title{
Predictive role of loco-regional radiotherapy among metastatic breast cancer patients who had undergone primary tumor surgery
}

\author{
Kadri Altundag ${ }^{1}$
}

Received: 1 August 2017/Accepted: 31 August 2017/Published online: 5 September 2017

(C) Springer Science+Business Media, LLC 2017

\section{Dear Editor,}

I want to congratulate Yoo and colleagues for their article [1] in which they developed and validated a predictive model to identify long-term survivors among metastatic breast cancer patients who had undergone primary tumor surgery. Among these patients, advanced T-stage, highgrade tumor, lymphovascular invasion, negative estrogen receptor status, high $\mathrm{Ki}-67$ expression, and abnormal CA 15-3 and alkaline phosphatase levels were associated with poor survival. However, the authors did not mention frequency of patients who received loco-regional radiotherapy (RT) which may affect survival of these patients. As associated with this, medical records of 227 patients with de novo stage IV breast cancer between April 1999 and January 2013 were retrospectively evaluated in our study [2]. In our study population, $188(82.8 \%)$ patients had locoregional treatment (LRT) [2 (1\%) had loco-regional RT alone, 54 (29\%) had surgery alone (mastectomy, $n=50$; breast-conserving surgery (BCS), $n=4)$, and $132(70 \%)$ had surgery (mastectomy, $n=119$; BCS, $n=13$ ) followed by loco-regional RT]. The median follow-up time was 35 months (range 4-149 months). The 5-year OS and PFS rates were significantly higher in patients treated with loco-regional RT than the ones who were not. In conclusion, our study results supported that addition of loco- regional RT increases the survival of metastatic breast cancer patients who had undergone primary tumor surgery. Therefore, loco-regional RT might be considered as an important independent variable to predict survival.

\section{Compliance with ethical standards}

Conflict of interest Kadri Altundag has no conflict of interest to declare.

Ethical approval This manuscript complies with the ethical rules applicable for this journal.

Human and animal rights This article does not contain any studies with human participants or animals performed by any of the authors.

\section{References}

1. Yoo TK, Chae BJ, Kim SJ, Lee J, Yoon TI, Lee SJ, Park HY, Park HK, Eom YH, Kim HS, Kim CJ, Shin MS, You SH, Song BJ (2017) Identifying long-term survivors among metastatic breast cancer patients undergoing primary tumor surgery. Breast Cancer Res Treat 165(1):109-118

2. Gultekin M, Yazici O, Eren G, Yuce D, Aksoy S, Ozisik Y, Guler N, Yazici G, Hurmuz P, Yildiz F, Altundag K, Gurkaynak M (2014) Impact of loco-regional treatment on survival in patients presented with metastatic breast carcinoma. Breast 23:775-783
Kadri Altundag

altundag66@yahoo.com

1 MKA Breast Cancer Clinic, Tepe Prime, Cankaya, Ankara 06800, Turkey 